WellBeing International

WBI Studies Repository

$2-2006$

\title{
Grey Parrot (Psittacus erithacus) Numerical Abilities: Addition and Further Experiments on a Zero-Like Concept
}

Irene M. Pepperberg

Brandeis University

Follow this and additional works at: https://www.wellbeingintlstudiesrepository.org/acwp_asie

Part of the Animal Studies Commons, Comparative Psychology Commons, and the Other Animal Sciences Commons

\section{Recommended Citation}

Pepperberg, I. M. (2006). Grey parrot (Psittacus erithacus) numerical abilities: Addition and further experiments on a zero-like concept. Journal of Comparative Psychology, 120(1), 1.

This material is brought to you for free and open access by WellBeing International. It has been accepted for inclusion by an authorized administrator of the WBI Studies Repository. For more information, please contact wbisr-info@wellbeingintl.org.

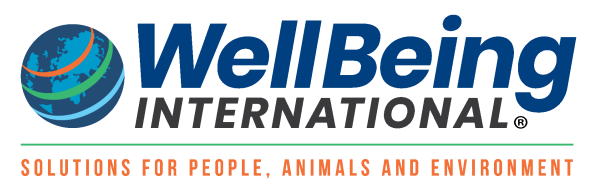




\title{
Grey Parrot (Psittacus erithacus) Numerical Abilities: Addition and Further Experiments on a Zero-Like Concept
}

Irene M. Pepperberg

Brandeis University and Radcliffe Institute for Advanced Study

KEYWORDS

nonhuman number concepts, parrot cognition, avian intelligence

\begin{abstract}
A Grey parrot (Psittacus erithacus), able to quantify 6 or fewer item sets (including heterogeneous subsets) by using English labels (I. M. Pepperberg, 1994), was tested on addition of quantities involving $0-6$. He was, without explicit training, asked, "How many total $X$ ?" for 2 sequentially presented collections (e.g., of variously sized jelly beans or nuts) and required to answer with a vocal English number label. His accuracy suggested (a) that his addition abilities are comparable to those of nonhuman primates and young children, (b) some limits as to his correlation of "none" and the concept of zero, and (c) a possible counting-like strategy for the quantity 5.
\end{abstract}

Studies of number concepts in animals, particularly those involving nonhuman primates (e.g., Boysen \& Hallberg, 2000), have been suggested as a means to examine the evolution of numerical processes in humans. According to some researchers, animals' number sense is a neurally based, evolutionarily inherent skill (e.g., Dehaene, 1997) on which human competence is based. Thus, the sensitivity to ordinality and numerosity demonstrated by apes, lions, monkeys, dolphins, pigeons, coots, crows, and rats should not be surprising (e.g., Beran, 2004; Biro \& Matsuzawa, 2001; Brannon \& Terrace, 2000; Judge, Evans, \& Vyas, 2005; Kilian, Yaman, von Fersen, \& Güntürkün, 2003; Lyon, 2003; McComb, Packer, \& Pusey, 1994; Nieder, Freedman, \& Miller, 2002; Olthof \& Roberts, 2000; Shumaker, Palkovich, Beck, Guagnano, \& Morowitz, 2001; Smith, Piel, \& Candland, 2003; Thompson, 1968; Xia, Emmerton, Siemann, \& Delius, 2001; for additional references, see Pepperberg \& Gordon, 2005; cf. Dehaene, 2001). Several researchers, however, consider more advanced numerical abilities - exact counting of quantities of four or more and arithmetic operations-to be uniquely human and based on language skills (Spelke \& Tsivkin, 2001).

In this view, language, in conjunction with cognitive systems present in humans and other animals, underlies humans' unique development of number knowledge. Supposedly, for animals and young children ( $\leq 3$ years), one form of language-independent representation handles exact numerosities up to and including four by tracking distinct individual members of a set (i.e., items are not seen as a set); 
another language-independent system dealing with approximate numerosity takes over for larger quantities. The latter system fails to represent each set member as a persisting individual (Spelke \& Tsivkin, 2001) and thus cannot accurately track amounts over four (e.g., a set can be judged as more or less than other sets, but the specific amount cannot be determined). These systems seem to relate, respectively, to subitizing and estimating (Davis \& Pérusse, 1988), subitizing being defined (e.g., Kaufman, Lord, Reese, \& Volkmann, 1949) as a fast, effortless, and accurate perceptual apprehension of number usually of four or less that uses preattentive mechanisms and generally involves linear or canonical patterns of objects (think dice or dominoes); and estimation being a perceptual apprehension of larger numbers, influenced by density and the regularity of the objects' distribution that enables approximations (e.g., between 80 and 100; see Dehaene, 1997, pp. 70-72). In this view, language abilities involving reference and ordering of labels that emerge as children mature allow them to integrate knowledge of quantity in the small sets with their initially rotely memorized number sequence to form 1:1 correspondences - that is, generate symbolic representations of number-that can be extended to larger amounts and thus achieve exact accuracy for sets above four (Carey, 2004; Carey \& Spelke, 1994; Spelke \& Tsivkin, 2001). Other researchers have offered somewhat differing explanations of how children acquire the ability to symbolize number, to count, and to do arithmetic (e.g., suggest use of spatial skills, such as number lines), but they agree that most animals do not exhibit such behavior, at least for numbers greater than four (e.g., review in Mix, Huttenlocher, \& Levine, 2002). ${ }^{1}$

Animals trained with human-based symbolic systems using Arabic numerals (chimpanzees: Boysen \& Berntson, 1989; Matsuzawa, 1985) or with human speech including number words (Grey parrots: Pepperberg, 1987, 1994) would, however, seem to provide intermediary links between animals lacking such training and children. Chimpanzees can both choose Arabic numerals to quantify a collection from zero to eight (production) and pick the appropriate collection of items after seeing an Arabic numeral (comprehension; zero to three: Boysen \& Hallberg, 2000; one to nine: Biro \& Matsuzawa, 2001; note Beran \& Rumbaugh, 2001). At least one Grey parrot vocally has produced English quantity labels to identify sets of six or fewer items, including novel items, random patterns, and subsets of heterogeneous groups (e.g., number of blue blocks within groupings of blue and green blocks and balls, Pepperberg, 1994) and has demonstrated comprehension of these vocal numbers, including some simple understanding of a zero-like concept (Pepperberg \& Gordon, 2005). In all cases, although these animals have both successfully used human symbols and exceeded the four-unit stricture suggested as the divide between animal and human number competence, the extent to which they understand and use number when compared to young children (e.g., Mix et al., 2002) is still unclear.

For example, only one study, on an ape, involved summation and required that the animal symbolically label the sum (Boysen \& Berntson, 1989); the study, however, used a quantity totaling only four. Other studies, involving additive and subtractive tasks and using larger numbers of objects (up to 10), used only one type of token and required subjects to choose the larger amount, not label the final quantity (e.g., Beran, 2001, 2004; Rumbaugh, Savage-Rumbaugh, \& Hegel, 1987; Rumbaugh, Savage-Rumbaugh, \& Pate, 1988). ${ }^{2}$ This procedural difference is important. When only one type of token (e.g., marshmallows) is used in studies of relative amounts, evaluations of contour and mass, rather than number, could be responsible for the responses (Rousselle, Palmer, \& Noël, 2004; see review in Mix et al., 2002), as was the case for pigeons (Olthof \& Roberts, 2000). In these studies, however, the close phylogenetic relationship between apes and humans (Olson \& Varki, 2004) and knowledge of the similarities between hierarchical demands of the apes' ecological and social structures and those of early humans (foraging priorities, fission-fusion relationships; Boysen \& Hallberg, 2000; Rumbaugh et al., 1987), as well as recent studies on possible parallels in brain areas underlying numerical judgments in humans and monkeys (Göbel \& Rushworth, 2004; also Dehaene, Piazza, Pinel, \& Cohen, 2003), suggest that such 
data reflect an evolutionary continuum in numerical abilities. Whether such a continuum extends to nonprimates is unclear.

It is of interest to note that not all the arithmetical studies cited above involved the quantity zero. Zero is unique in that counting and adding presuppose something to add or count, and the absence of quantity seems to present some initial confusion for children (see Bialystok \& Codd, 2000). Apes' use of zero has not been shown to be fully equivalent to that of humans. Thus, although the chimpanzee Sheba was tested with the placard " 0 " in her addition trials and could match a single empty food tray to this placard, she never had to respond to the total absence of objects to be added (Boysen \& Berntson, 1989). In the Rumbaugh et al. $(1987,1988)$ studies, the chimpanzees Sherman and Austin had to choose the greater quantity between two collections in which one food well could be empty but were not asked to label the results; Beran's $(2001,2004)$ studies also did not involve labeling zero. And Ai, who was trained to both produce and comprehend zero with respect to the absence of quantity, was not tested on zero in terms of arithmetic (Biro \& Matsuzawa, 2001).

I now report evidence to suggest that a Grey parrot, Alex, a creature with considerable evolutionary distance from both human and nonhuman primates, but with similar ecological demands and possibly similar social structures in nature (Pepperberg, 1998), demonstrates, without training, summation capacities comparable to those of nonhuman primates, involving labeling of amounts up to six. Of interest was that these experiments were unplanned. My students and I had begun a sequential auditory number session (training to respond to, for example, three computer-generated clicks with the vocal label "three") with another bird, Griffin, in the standard manner, by saying "Listen," clicking (this time, twice), and then asking "Griffin, how many?" Because Griffin refused to answer, we replicated the trial. Alex, who often interrupts Griffin's sessions with phrases like "Talk clearly" or who occasionally answers even though he is not part of the procedure, said "four." I told him to be quiet, assuming that his vocalization was not intentional. We then replicated the trial yet again with Griffin, who remained silent; Alex now said "six." I thus decided to replicate the Boysen and Berntson (1989) study as closely as possible under constraints of having a subject who was not allowed to move about the laboratory on his own and to extend the study to further work on zero. Data from these experiments not only demonstrated Alex's competence in addition, but also present intriguing evidence that he may use a counting-like strategy for the quantity five and that his concept of zero, although closely related to absence, is not as fully developed as that of humans.

\section{Method}

\section{Subject and Housing}

Alex, a 28-year-old male Grey parrot (Psittacus erithacus), had been the subject of cognitive and communicative studies for 27 years, including those involving numerical competence (Pepperberg, 1987, 1994; Pepperberg \& Gordon, 2005). Testing locations and living conditions when neither testing nor training was in progress were described in Pepperberg and Wilkes (2004). Food and water were available at his vocal request at all times during testing. In this study, he used his previously documented ability to vocally label quantities up to and including six (Pepperberg, 1994).

\section{Apparatus}

Testing involved familiar objects. The tray that formed the substrate for all trials had been used for previous studies on label comprehension (Pepperberg, 1990, 1992), object permanence (Pepperberg \& Kozak, 1986), and other number capacities (Pepperberg, 1994; Pepperberg \& Gordon, 2005). I, along with other trainers, concurrently used the same tray for training spatial concepts and phoneme and Arabic 
number recognition (e.g., Pepperberg, in press-a, in press-b), so the tray was not a cue for addition. Plastic cups used to cover items to be added were also familiar, being the subject of queries on color and on the concepts of same versus different and relative size, and used as containers for object permanence and in concurrent training for a recursion study. ${ }^{3}$ Items to be summed were familiar treats (e.g., candy hearts, variously sized jelly beans, pieces of nuts). Such items were used rather than the usual nonfood objects because of their small size and their interest to the parrot. Note that only the hearts were of one consistent size, so that tasks generally involved objects of different mass and contour.

\section{Procedure: Object Presentation}

In the absence of any prior training, an addition trial began when an experimenter, out of Alex's line of sight, placed objects, counterbalancing number sets on the right and left across trials, onto the surface of the tray and covered the items with plastic cups. When multiple objects were placed under a single cup, each object was spaced less than $1 \mathrm{~cm}$ from other nearest items, and generally, the distance was less. The experimenter brought the tray up to Alex's face, lifted the cup on Alex's left, showed him what was under the cup for 2-3 s in initial trials, and then replaced the cup over the quantity; the procedure was replicated for the cup on Alex's right. In trials comprising the last third of the experiment, Alex was given approximately 10-15 s to view the items under each cup. The experimenter made eye contact with Alex, who was then asked, vocally, and without any training, to respond to questions, such as "How many nut total?" No objects were visible during questioning. He had previously demonstrated he could respond vocally to our queries (Pepperberg, 1999). To respond correctly, he had to remember the quantity under each cup, perform some combinatorial process, and then produce a label for the total amount. He was not given any time limit in which to respond, but if he did not answer within about $5 \mathrm{~s}$, the question was restated; if he grabbed and overturned a cup, the objects were covered, he was shown both sets of objects sequentially, and the question was restated. Given that his time to respond was generally correlated with his current interest in the items being used in the task, rather than the task itself (Pepperberg, 1988), I did not record latency to respond.

\section{General Testing Procedure}

Test sessions on a single numerical array of various object collections occurred on average 2-5 times a week from June 2004 to January 2005, with breaks for student vacations, intersessions, and a hiatus from November 2004 through mid-January 2005. ${ }^{4}$ Test questions were presented intermittently either during free periods (when birds were requesting various foods or interactions) or during sessions on current (and thus unrelated) topics (e.g., using Alex to assist in training another parrot on color labels) until all questions for the experiments were presented.

Details of test procedures, including descriptions of precautions against inadvertent and expectation cuing, can be found in Pepperberg $(1981,1990,1994)$; summaries are below. A trial would be repeated in a session only if Alex's initial answer was incorrect or if his grabbing a cup required re-presentation as noted above (e.g., Pepperberg, 1981, 1987). Thus, the number of times an array was presented to Alex generally depended on his accuracy. If Alex produced the appropriate label, he received praise and the objects to which the question referred or was allowed to request an alternative reward. No further

presentations of the same material then occurred; that is, there was only a single "first trial" response. If an identification was incorrect or indistinct, the examiner removed the tray of objects, turned his or her head, and emphatically said "No!" This procedure was used in order to penalize a "win-stay" strategy, and presentation continued until a correct identification was made or four attempts occurred; errors were recorded. 
As in all studies with Alex, the protocol differed from ones used with other animals in two respects. First, the task capitalized on Alex's ability to work in the vocal mode; second, each trial was presented intermittently during training and testing of other unrelated topics also under study. Alex's responses thus had to be chosen from his entire repertoire (more than 90 vocalizations, including labels for foods and locations) and from among numerous possible topics concerning various exemplars and questions during each session; that is, Alex had to attend to the specific type of question being posed. This design not only increased the complexity of the task, but prevented several forms of cuing (see below; see also Pepperberg, 1999; Premack, 1976, p. 132).

\section{Controls Against Expectation and Experimenter-Induced Cuing}

Test situations included specific precautions to avoid cuing. One control was a design such that each test session was, as noted above, presented intermittently during free periods or work on unrelated topics. An examiner who, for example, poses a series of similar questions may come to expect a particular answer and unconsciously accept an indistinct (and, by our criteria, incorrect) response of, for example, "gree" (a mix of "green" and "three") for "green." As noted above, Alex's responses had to be chosen from his entire repertoire and from among numerous possible topics during each session; each session contained only a single number array. Second, in general, an experimenter other than the one presenting the tray (one of five possible individuals in these studies), who did not know what was on the tray, confirmed the answer; his or her interpretation of Alex's response was thus unlikely to be influenced by expectation of a certain number label. Only after his or her confirmation was Alex rewarded (Pepperberg, 1981). Third, this evaluator was unlikely to be influenced by hearing the type of question posed: In a previous study, transcriptions of contextless tapes of Alex's responses in a session agreed at a rate of $98.2 \%$ with original evaluations (Pepperberg, 1992). ${ }^{5}$ Fourth, because Alex had not been trained on this task, no overlap occurred between training and testing situations, and because training on number labels had occurred years before, Alex could not have picked up on trainer-induced cues specific to a given label (Pepperberg, 1981); moreover, because a total of six different experimenters were involved in the testing, the presence of a particular individual could not cue a number session. Fifth, I also used several different common treats in testing, including those used for training the other birds (e.g., various jelly beans for training on colors); thus, particular objects would not cue Alex that a number test was in progress. Not even the specific concatenation of tray, cups, and treats could cue him, as the arrangement was not exclusively used on number trials (e.g., it was similar to that used in the recursion study in progress) and thus did not signal a number test.

Approximately $15 \%$ of trials were videotaped to check further for cuing and interobserver reliability. I used video so as to be able to check for Alex's attention and motivation. One trial was discarded from the addition analysis because Alex was indeed not attending to the tray, but the trial was kept for an interobserver reliability check because of the clarity of the response. Observers for reliability did not watch the video but listened as if they were scoring in the laboratory, stating what they heard Alex say. If interobserver reliability with blind coders was high, I could be assured of the validity of other trials. Given that Alex was far more interested in the human who was taping as well as the camera and mike than in the objects to be enumerated, such trials were difficult to execute and were kept to a minimum.

\section{Scoring}

Alex's test scores were calculated in two ways. Because the test procedure required that, if Alex erred, a question could be repeated (up to four times) until he produced the correct response, I scored both first trial and all trial responses. First trial results were the percentage of correct responses on first trials. The overall test score (results for all trials) was obtained by dividing the total number of correct identifications 
(i.e., the predetermined number of collections) by the total number of presentations required to obtain the correct responses. Statistics were performed on first trials only.

To learn whether Alex's results were statistically significant, I used two binomial tests. In one, chance $(1 / 6)$ was based on number of labels (six) relevant to the task - that is, as if Alex was randomly guessing among all number labels after hearing "How many X total?" A second, more conservative test used a larger value of chance (1/3), as though Alex were choosing to respond with one of the two viewed quantities (the addends) without summing, as well as the possible answer. The least conservative calculation (not performed) would include the probability of his producing any of the approximately 100 labels in his repertoire; all calculations assumed that Alex would always $(p=1)$ attend and respond correctly to the "How many . . . ?" question (i.e., not provide a random label that had no connection to the task at hand).

\section{Experiment 1: Addition}

\section{Method}

Experiment 1 consisted of 48 trials using the procedures described above. I presented each total amount eight times, in random order, in sets of six, such that no collection was shown sequentially. Addends were displayed an equal number of times, such that, for example, amounts adding to 6 were presented as $6+0,5+1,4+2$, and $3+3$, two times each, with quantities alternating under right and left cups; amounts adding to 5 were displayed as $5+0,4+1,3+2$, and so forth; I could present 1 only as $1+0$, randomizing quantity under right and left cups (N.B., unless otherwise stated, all $X+Y$ collections refer to both $X+Y$ and $Y+X$ forms). All possible addend collections were also randomized; thus, the preponderance of $X+0$ trials at the end of the study occurred by chance. A full list of trials is given in the Appendix. On a given trial, I generally used objects differing in size; for example, I used both small and large jelly beans or irregular nut pieces to avoid issues of mass and contour. In six trials, I used identical candy hearts to see whether Alex would be more accurate if he could use mass or contour. The number of trials was deliberately kept low to avoid training. Finding the intriguing behavior on $5+0$ sets (see below), I began giving Alex more time (approximately 10-15 s) on these and all subsequent trials, noted by an asterisk in the Appendix, and replicated the earlier $5+0$ trials under the longer time interval.

\section{Results}

Alex's scores were calculated several ways and examined for several types of issues (see Table 1). Retaining the errors for the $5+0$ trials given under the 2- to 3-s interval, I found that Alex's accuracy was 41 of 48 , or $85.4 \%$ for first trial responses ( $p<.005$; binomial test, chance of $1 / 3$ or $1 / 6$ ), and 48 of 60 , or $80 \%$ for all trials. If replications of the $5+0$ trials under the longer time interval are substituted, his first trial accuracy was 43 of 48 , or $89.6 \%(p<.005)$, and 48 of 53 , or $90.6 \%$ for all trials. His accuracy for small quantities $(1,2)$ was 15 of 16 , or $93.8 \%(p<.005)$; his accuracy for large sums $(5,6)$ when given the longer time period was 13 of 16 , or $81.3 \%(p<.005)$; the difference is nonsignificant (comparing errors and correct scores for small vs. large trials, $p=.599$, Fisher's exact test); note, too, that all the errors for the larger sums involved apparent labeling of the addends before labeling the total. Of particular interest was his score for his first six trials, that is, the first time he was presented with each of the sums; his accuracy was 5 of 6 , or $84.3 \%$ ( $p<.02$; binomial test, chance of $1 / 3)$. Using candy hearts did not help him with the second $5+0$ trial or the single $3+1$ error. Although he did not err on any of the other four trials using hearts, the number of errors overall was too small to suggest that using objects of equal mass and contour made any difference. It is interesting to note that three of his four errors on queries other than $5+0$ involved situations where the larger addend was on his left, that is, in reverse of the ordinal number line; however, he was correct on 18 of these reversed-order trials, suggesting that the errors were 
random (comparing errors and correct scores for reversed vs. nonreversed trials, $p=.606$, Fisher's exact test). Initially, when given only $2-3 \mathrm{~s}$, he was always wrong on the $5+0$ sum, consistently stating "6." When given 10-15 s, his accuracy went to $100 \%$ on $5+0$ and $0+5$ trials; the difference in accuracy between the shorter and longer interval trials was significant (counting all queries for $0+5$ and $5+0$, Fisher's exact test, $p=.01)$. For other trials, he went from 26 of $29(89.7 \%, p<.005)$ for $2-3 \mathrm{~s}$ to 15 of 17 $(88.2 \%, p<.005)$ for $10-15 \mathrm{~s}$, essentially remaining constant.

Also of interest were interobserver reliability checks on his videotaped responses. Five different observers from the Radcliffe Institute (four female, one male) completely unfamiliar with Alex's speech patterns listened to a tape for each of Alex's number labels. On one trial, two said they could not hear Alex's response, but the other three correctly identified the label as "three." On the trial for "five," the male observer misidentified the label, but on trials for the other numbers, all observers correctly identified all the labels that Alex produced. If I collapse all trials over all listeners, omitting the two trials from the listeners who could not hear the response, interobserver reliability is $96.4 \%$ (i.e., observers agreed on 27 of 28 trials).

Table 1. Results and Errors for Experiment 1

\begin{tabular}{|ccccll|}
\hline Sum & Score & $\%$ & $\boldsymbol{p}^{\mathbf{a}}$ & Trial type error & Error descriptions \\
\hline 1 & $8 / 8$ & 100.0 & $<.005$ & & \\
2 & $7 / 8$ & 87.5 & $<.005$ & $1+1$ & 5 \\
3 & $8 / 8$ & 100.0 & $<.005$ & & \\
4 & $7 / 8$ & 87.5 & $<.005$ & $3+1$ & 3 (seemed to label addend) \\
5 & $4 / 8$ & 50.0 & .25 & $3+2(2$ times) & \\
& & & & $5+0\left(^{\mathrm{b}}\right.$ times) & $2 ; 3$ (seemed to label addends) \\
& $7 / 8$ & 87.5 & $<.005$ & $3+3$ & 3 (4 times); 6 (4 times) \\
\hline
\end{tabular}

${ }^{a}$ Calculated on the basis of $1 / 3$, the stricter criteria.

${ }^{\mathrm{b}}$ Note that if only these errors were counted, and the correct responses for $5+0$ trials were repeated under longer time trials, Alex's score would have been $6 / 8$, or $75 \%$, and his $p$ value would have been .02 .

${ }^{c}$ Under 2- to 3-s time limit; when trials were repeated with longer times, Alex was correct.

\section{Discussion}

Alex demonstrated some competence in summing small quantities. His results seemed independent of the number or type of objects involved, with the exception of the $5+0$ trials given in 2-3 s that he labeled as "six," and some trials involving the quantity three where he seemingly labeled the addends before providing the sum. If the long-interval $5+0$ trials are used, he was as accurate on small quantities involving one or two as he was on those summing to five or six. His performance was apparently independent of mass or contour; having equal mass or contour did not help him when the time was restricted for $5+0$. Thus, in general, his data are comparable to that of young children (Mix et al., 2002) and chimpanzees (Boysen \& Hallberg, 2000).

The mechanism that Alex used cannot easily be determined; the data suggest he might have used different mechanisms in different situations. Although I have no evidence that he can count exactly as do humans (see Fuson, 1988) - that is, (a) produce a standard sequence of number tags, (b) apply a unique number tag to each item to be counted, (c) remember what already has been counted, and (d) know that 
the last number tag used tells how many objects are there-he may have used a related strategy in some trials. I discuss various possibilities below.

Might Alex have used a nonverbal accumulator? This system was initially proposed as a means to enumerate sets of discrete events (numbers of sequential tones, a continuous amount of time; a switch gates one pulse per event into an accumulator at a constant rate; its fullness indicates the total amount; Meck \& Church, 1983). It is generally posited as a mechanism for comparing sequential sets or preverbal counting (e.g., Gallistel \& Gelman, 1992). To use an accumulator, Alex would have to visually partition and scan individual items in each addendum at a constant rate (an event for each pulse) and not reset his accumulator for the second addendum. The system is inherently inexact because of the variability in scanning sets of static items (i.e., the rate of pulses; see Mix et al., 2002); it produces errors normally distributed around the correct response and shows increasing errors with increasing set size, specifically above three; it would not provide the exact numerosities Alex's task requires. Note that Alex did not make more errors for larger quantities.

For collections involving $X+Y, Y \neq 0$, he might have formed representations in memory for each addend and then recalled them as a total quantity to be labeled. He could begin with object files for the individual addends (pointers enabling the brain to keep track of particular objects; e.g., Dantzig, 1930; Kahneman, Treisman, \& Gibbs, 1992; Thomas, 1992; Trick \& Pylyshyn, 1994) or some more imagistic model (of the whole scene; e.g., Uller, Carey, Huntley-Fenner, \& Klatt, 1999), then switch to a process posited by Huttenlocher, Jordan, and Levine (1994), wherein (total) representations now provide conceptual referents for count words (Mix et al., 2002); this process is proposed for children who are just beginning to correlate count words and numerosities of four or more. In general, object files are posited for quantities of four or fewer, and quantification involving such files is assumed to occur speedily (see Mix et al., 2002). Only for the $5+1$ set would Alex see an addend above four; he could have replied "six" simply because he saw a large grouping (greater than four) and used, by default, his largest vocal number label. Note that Ai responded more accurately and faster on the largest number, relative to the next largest number, during training to expand her range of number labeling (Murofushi, 1997), suggesting a similar mechanism. A comparable result may be seen for adult humans (Balakrishnan \& Ashby, 1991; Simon \& Vaishnavi, 1996). Alex's ability to respond correctly for $4+1$ sets, even under time constraints, suggests that he might use either a five-member object file or some form of representational summing in memory; remember, no time constraints existed for his response.

Note that four of five errors on $X+Y$ trials involved labeling one or both addends (particularly that of "three") before producing a correct response; the behavior occurred for $3+1,3+2$, and $3+3$. It is interesting to note that in the two $3+2$ cases, the addend labels were produced after Alex beaked the cups and lifted them on his own before answering. Possibly this combination, summing to five, was particularly difficult, but he did correct himself, unlike the case for $5+0$. Also, if only these errors and results for $5+0$ when he was given 10-15 s are counted, his score for sums of five would be 6 of 8 , or $75 \%$ ( $p=.02$; binomial test, chance of $1 / 3$ ), suggesting that a sum to five was not, in and of itself, particularly difficult; he did not err on $4+1$. Why he labeled three when it was an addend, in 4 of 10 instances, and, in general, did not do so with other addends, is unclear. Given that his response on the very first trial, "three," garnered excessive praise from testers, possibly some interference occurred that made production of the label difficult to inhibit whenever he viewed the quantity in these circumstances.

For most $X+0$ collections, he might have subitized. In general, reaction times are used to distinguish counting from subitizing (e.g., Mandler \& Shebo, 1982; Trick \& Pylyshyn, 1989, 1994), but Alex cannot be evaluated on latency to respond: His response times correlate with his desire for the rewards (Pepperberg, 1987, 1988). Here, however, I initially constrained viewing time to 2-3 s, restricting his time to interpret what was being presented. Thus, for $X+0$, he might, as do humans, have subitized $X=1$ to 
4. Also, when given only 2-3 s, he may have perceived five as "lots" and, knowing "six" was his largest label, used it as a default for anything above four. He did not simply confuse five and six; he never said "five" for six items. Given 10-15 s for $5+0$, he was correct, which suggests that he used additional time to his advantage, maybe like 4- to 5-year-old children who were more accurate on five-element arrays when given additional time (Gelman \& Tucker, 1975).

The mechanism for the $5+0$ trials is unclear. He did not subitize, precisely because he needed extra time beyond that required for four items. If he used Huttenlocher et al.'s (1994) mental model, would inclusion of only one item beyond four increase the time needed to recall and match a label to the five-item model? If such a model existed, it would have been created to respond correctly in earlier number production and comprehension studies in which he easily labeled five items (e.g., Pepperberg, 1987, 1994; Pepperberg \& Gordon, 2005); Alex would not likely have needed extra time here. And according to researchers who study clumping or chunking in adults-dividing a set of four or more into smaller groupings that are subitized and then summed (von Glasersfeld, 1982)_Alex would not have needed more than 2-3 s for that mechanism unless he responded like young children, who may need more time to segment four or five items into smaller subitizable units than do adults (Fischer, 1992). Dehaene (1997), however, argued that the additional time needed or the decrease in accuracy when children subitize four rather than three or fewer items has to do with four being a boundary between subitizing and estimating, not with chunking. Also, in all discussions of subitizing versus other strategies, adults' subitizing supposedly occurs during a time course of at most a few hundred milliseconds (i.e., generally less than $0.35 \mathrm{~s}$ for four and less than $0.70 \mathrm{~s}$ for five; see Mandler \& Shebo, 1982); in all cases, Alex had considerably more time available. Nevertheless, it is conceivable that Alex needed more than a few seconds to individuate the set of five elements, so that he could then use a noniterative (noncounting) mechanism (for comparisons with children, note Huntley-Fenner, 2001).

Might Alex have analyzed $5+0$ in stages during a longer time interval? Maybe he first rejected "four," which he can subitize, next dismissed the impulse to respond with his largest label, and then finally responded by recalling a model for five. This procedure would explain the time delay but not why he did not initially use the model if it existed for five, or why he persisted with "six" even when told he was wrong during the shorter time interval. Having been shown the sets four times in those trials, he would have had a total exposure equal to that of the single longer time interval.

During the longer times for $5+0$, Alex might have used a form of nonvocal tagging, approaching that of human counting. Work in progress shows that, despite lack of ordinality training, he understands which of two Arabic numerals represents the larger or smaller quantity (Pepperberg, in press-b). Such data suggest that he knows ordinal relationships among his numbers even if he cannot vocally recite a standard number sequence. A counting-like strategy may be one logical interpretation. Preschoolers' understanding of counting is enhanced when it is embedded in a number-relevant reasoning task, such as addition or subtraction (Zur \& Gelman, 2004); possibly this was true for Alex. His $5+0$ trials, by chance, did not occur until about half the trials were completed and thus until he had considerable experience with addition. Also, counting may be facilitated by an ability to subitize and sum small groups of items and by specific processes of recitation (nonverbal tagging) and attention (segmentation) (e.g., Piazza, Giacomini, Le Bihan, \& Dehaene, 2003). Nevertheless, being able to label a collection correctly, even one larger than four, does not mean, even in children, full understanding of counting. Children who correctly respond to "How many?" may fail on "Give me X" because they associate collections and labels but do not fully comprehend the connection between cardinality and counting-they do not understand, for example, how to count to form a specified collection (review in Sophian, 1995).

I do propose, nonetheless, that Alex used some counting-like strategy for $5+0$ sets. His accuracy on $4+1$, but not $5+0$, under constrained viewing, not response, time suggests he can track quantities up to 
four, remember them, and then mentally sum them to give a correct response. He did not need anything else for collections summing to, but not including, five, because no time constraint existed on summing. His general accuracy on $2+3$ may also support this claim; labeling the addends may have assisted memory. His need for extra viewing time only for $5+0$ suggests he used a different strategy. As for Fischer's (1992) argument for chunking, chunking is unlikely to take much longer than the 2-3 s Alex was initially given; his use of a counting-like strategy could have required the extra time.

Even if Alex were counting, his use of a "counting on" strategy (Baroody \& Dowker, 2003; Fuson, 1988; Groen \& Parkman, 1972; Groen \& Resnick, 1977) is unlikely. Such a procedure involves representing one addend, for example, "three," either by subitizing or counting, then sequentially denoting each element in the next addend, for example, "four, five" to give a total, "five." Older children (e.g., first graders) usually start with the larger set (Ashcraft, 1982; Groen \& Parkman, 1972; Siegler, 1987); if Alex did so he might have made significantly fewer errors when shown a larger set first (a reversal of the number line), but he did not. Given that, as noted above, I lack data to suggest that Alex produces a standard counting sequence, he probably does not "count on." Children generally do not fully understand this procedure until they are 5 or 6 years old (Bialystok \& Codd, 1997); thus, Alex's lack of this mechanism would not be surprising.

\section{Experiment 2: Concept of Zero}

\section{Method}

Experiment 2 consisted of eight trials, interspersed randomly within those of Experiment 1, designed to examine Alex's concept of absence of number. Alex had never had formal instruction on a zero concept. $\mathrm{He}$ had, on his own initiative, begun to use "none" spontaneously to refer to the absence of a particular number of objects on a tray during a study of number comprehension (Pepperberg \& Gordon, 2005). He subsequently succeeded in additional trials in this format, stating "none" to questions about, for example, five items when two, three, and six item sets were present. Now I presented questions of "How many bean [or nut or heart]?" and put nothing under any of the cups. The goal was to determine the extent to which he could generalize the use of "none" without instruction.

\section{Results}

On the first four trials, Alex simply looked at the tray and said nothing. He would sometimes try to lift the cups himself, and I would then show him again, by lifting the cups one at a time, that there was nothing present. On the fifth, sixth, and seventh trials, he said "one." On the last trial, he again refused to answer.

\section{Discussion}

Zero is interesting because it lacks concrete reality and thus may emerge for children later than other numerical concepts (Bialystok \& Codd, 2000; Wellman \& Miller, 1986); specifically, as noted above, numerical competence is based on the assumption that something exists to enumerate, whatever the process involved. My asking Alex to enumerate something that did not exist clearly presented a challenge. As noted above, the question was related to that of a previous study (Pepperberg \& Gordon, 2005)—for example, "What color [is the collection of] five [items]?"-when there were not five of anything (e.g., in a collection of two purple blocks, three green blocks, and six orange blocks), but for those trials many objects were present; here, nothing was present other than the two cups to which he had habituated. Unlike nonhuman primates in other studies, Alex had had no formal training on the zero concept. In contrast, the chimpanzee Sarah had received extensive training on labeling arrays of candies and junk objects with Arabic numbers, including zero (Boysen, 1993; Boysen \& Berntson, 1989), and Ai had similar production and comprehension trials on computer monitors (Biro \& Matsuzawa, 2001). 
Previous to this study, Alex had generalized his understanding of "none" as a trained response to the absence of information from questions on similarity and difference (Pepperberg, 1988) to, without training, relative size (e.g., to respond to "What color [object] bigger?" when two objects were identical in size; Pepperberg \& Brezinsky, 1991) and the aforementioned absence of numerical sets (Pepperberg \& Gordon, 2005).

Alex's two different responses were both intriguing. His failure to respond on five trials suggests he recognized something was different from the other trials; that is, even if he did not understand what was expected, he knew his standard number answers would not be correct. He did not, as he has done when bored with a task (e.g., Pepperberg, 1992; Pepperberg \& Gordon, 2005), give strings of wrong answers or request treats or to return to his cage. He acted more like autistic children (D. Sherman, personal communication, January 17,2005$)$ who simply stare at the questioner when asked "How many X?" and there is nothing to count. His response of "one" on the fifth, sixth, and seventh trials suggests a comparison to that of $\mathrm{Ai}$, who confused "one" with "zero." Although Alex was never trained on ordinality and had learned numbers in a random order (review in Pepperberg, 1999), he, like Ai, seemed to grasp that "none" and "one" represented the lower end of the number spectrum. As noted earlier, Alex previously used "none" to denote absence of a designated number of items (Pepperberg \& Gordon, 2005), which was a logical extension of his use of "none" to mark the absence of sameness or difference with respect to various attributes of object pairs, including absence of a size difference. Here he was asked to denote the total absence of labeled objects, a different task.

Stating this situation slightly differently might provide clarification: Previously he showed he recognized when there were not, for example, three of anything or attributes in common for an object pair; that is, he could search for a specific numerical set or a likeness or difference in existent object pairs and report on absence. Now he was asked to comment on items that simply did not exist. He had not been trained to use "none" this way. Note that he processed the query (e.g., "How many nut total?"), understanding that he was not asked to label the number of cups; he never said "two." Such data suggest that he views his number labels as an attribute of a collection. For Alex, the attribute can be missing from a collection and be labeled "none," but the missing object itself cannot be denoted as "none." The distinction is subtle. Specifically, Alex's use of "none" is not isomorphic with the adult human use of "zero," in that he does not use "none" as he does his number labels (e.g., Pepperberg, 1987) to denote a specific numerosity; that is, he does not view "none" as a numeral or numeric label. Nothing in his training would lead him to do so. In that sense, he is like humans in earlier cultures, who did not see zero as a quantity that could be labeled (Bialystok \& Codd, 2000). ${ }^{6}$

Arguably, had he responded "none," might an interpretation have been that he misunderstood the question-that is, assumed that I had asked "What color bigger/smaller?" or "What's different?" He had not, however, misunderstood the question in previous such trials; he never said "none" when two equal amounts were under the cups, and there was no reason to assume he would have misunderstood the question for this case. Moreover, he had previously demonstrated that he carefully attended to the several different questions I could ask about object pairs (e.g., "What toy?"; "How many?"; "What's same/different?"; and "What color bigger/smaller?" to two blocks of different colors and sizes; Pepperberg, 1999).

In sum, I suggest that his understanding of "none" as a zero-like concept with respect to absence may resemble that of young children, who seem to have to be about 4 years old before they achieve full adultlike understanding of labels for zero and other numerals (Bialystok, 2000; Bialystok \& Codd, 2000; Wellman \& Miller, 1986). Thus, whether Alex can acquire a full understanding of the equivalence of "none" to the concept of zero is still to be determined. 


\section{Conclusions and Future Directions}

This study demonstrates four previously unreported behavior patterns involving numerical competence in a nonhuman, nonprimate, nonmammalian subject. First, as noted above, I did not intend to examine Alex's abilities with respect to addition, but he gave evidence of such ability on his own. Second, Alex had to remember the addends and combine them to form a representation of the total, which is a more difficult task than simply labeling a visible set. Third, he demonstrated that his concept of zero is not isomorphic with that of adult humans, but does match that of young children and possibly apes. Finally, the data may provide evidence of a counting-like strategy.

Alex's considerable training on use of human number labels may, of course, have enabled him to use representational abilities that would otherwise have been inaccessible. As noted previously (Pepperberg \& Gordon, 2005), Alex has had over 2 decades of training on human vocal communication; he is thus similar to Matsuzawa's (1985) Ai, Boysen's (1993) Sheba, and Premack's (1976) and Boysen's (1993) Sarah. All such animals are special in their extensive enculturation to human cognitive tasks, and their achievements suggest that numerical concepts beyond those involving very small quantities (i.e., up to four) are functional in at least some nonhumans. The factor of enculturation is emphasized by data on the human Piraha tribe, who lack number labels and whose numerical abilities (they seem to have "one," "two," and "many," if that; Gordon, 2004) appear to be far less complex than those of enculturated nonhumans.

Most likely, animals' abilities to learn in the laboratory are based on an existent cognitive architecture (Pepperberg, 1999); their training merely provides a way to examine the extent to which this architecture matches that of educated humans (see Jarvis et al., 2005). For humans, data suggest that specific brain areas are involved in representations of numerical quantities, including addition (e.g., Dehaene et al., 2003; Lemer, Dehaene, Spelke, \& Cohen, 2003); how might a parrot brain function on tasks such as those given Alex? Does he have a homologue or analogue of human inferior parietal cortices, particularly the intraparietal sulcus (IPS) and inferior parietal lobule, the human areas supposedly tied to numerical competence (e.g., Lemer et al., 2003)? Note that many number comparison tasks involve issues of spatial attention and nonsymbolic comparisons, which are also correlated to IPS activity (Coull \& Nobre, 1998; Fias, Lammertyn, Reynvoet, Dupont, \& Orban, 2003; Göbel, Johansen-Berg, Behrens, \& Rushworth, 2004; Jordan, Schadow, Wuestenberg, Jeinze, \& Jäncke, 2004; Simon, 1999) ${ }^{7}$ and which are essential for nonhuman survival; thus, nonhumans are likely to have analogous brain areas (note Walsh, 2003). It is interesting to note that data from one study (Kawashima et al., 2004) suggest that the left intraparietal cortex is activated more in adults than in children during all numeric tasks, which suggests that either maturation or experience might be an issue (but see Spelke \& Dehaene, 1999). Might Alex's training -and that of other nonhumans given extensive training on numerical symbols (e.g., Biro \& Matsuzawa, 2001; Boysen \& Berntson, 1989)—have expanded capacities of these animals toward a representational ability more similar to that of humans than that which exists in untrained animals (Pepperberg, 1999; Pepperberg \& Gordon, 2005) or even untrained humans (Gordon, 2004)? Clearly, Alex's numerical abilities are not identical to those of children, but his exposure to and training on such tasks are also limited compared to that of an average preschooler. I suggest that whatever brain areas he uses do indeed function in an analogous manner to primates, given the similarities in data.

Clearly, additional studies are needed to determine the full extent of Alex's numerical capacities. I still need to determine whether he can learn both to produce and understand the meaning of an ordinal number sequence and to use "none" as a numeral. I need to study whether he can, like apes and young children, understand subtraction (e.g., Boysen \& Berntson, 1989, 1990; Fuson, 1988) and whether both addition and subtraction can be extended to symbolic use of his Arabic numbers. 
${ }^{1}$ Gallistel and Gelman (1992) argued for a preverbal counting mechanism that enables animals to perform some mathematical operations, but they (like other cited researchers) considered only small quantities and approximate answers for operations involving larger quantities. See Gelman and Cordes (2001) for an updated version of their thesis, including somewhat larger numbers (e.g., five).

${ }^{2}$ Other studies have used smaller quantities (e.g., 0-4) and will not be discussed because tasks involving these small quantities can be solved by perceptual mechanisms (see discussion in Beran, 2004).

3 Thus, Alex was used to having objects hidden under cups, knowing that hidden items had not disappeared, and being asked about hidden items.

${ }^{4}$ In late November 2004, Alex began to exhibit the same kind of inattention documented in Pepperberg and Gordon (2005); instead of persevering with trials that would then likely have to be discarded, I switched to testing on a different topic for 10 weeks.

${ }^{5}$ This percentage represented 106 matches of 108 vocalizations. As an additional control, the principal investigator made two transcriptions of a student, new to the lab, as he responded to the same type of questions as Alex. The first transcription was live; the second, made several days later, was of a tape from which all questions had been edited. The two transcriptions of the student's vocalizations matched to within $95.8 \%$ (68 of 71 vocalizations).

${ }^{6}$ Alexandrian Greeks, for example, used zero to denote the absence of quantity, but it did not function for them as a number (Kline, 1972).

${ }^{7}$ Note that Coull and Nobre (1998) have suggested that the left IPS is more active in temporal attention and the right IPS is more active in spatial attention, but Fias et al. (2003) found more activity in the left IPS for representation of symbolic and nonsymbolic magnitude. All cited studies do, however, implicate the IPS in numerical tasks.

\section{References}

Ashcraft, M. H. (1982). The development of mental arithmetic: A chronometric approach. Developmental Review, 2, 213-236.

Balakrishnan, J. D., \& Ashby, F. G. (1991). Is subitizing a unique numerical ability? Perception \& Psychophysics, 50, 555-564.

Baroody, A. J., \& Dowker, A. (Eds.). (2003). The development of arithmetic concepts and skills: Constructing adaptive expertise. Mahwah, NJ: Erlbaum.

Beran, M. J. (2001). Summation and numerousness judgments of sequentially presented sets of items by chimpanzees (Pan troglodytes). Journal of Comparative Psychology, 115, 181-191.

Beran, M. J. (2004). Chimpanzees (Pan troglodytes) respond to nonvisible sets after one-by-one addition and removal of items. Journal of Comparative Psychology, 118, 25-36.

Beran, M. J., \& Rumbaugh, D. M. (2001). "Constructive" enumeration by chimpanzees (Pan troglodytes) on a computerized task. Animal Cognition, 4, 81-89.

Bialystok, E. (2000). Symbolic representation across domains in pre-school children. Journal of Experimental Child Psychology, 76, 173-189.

Bialystok, E., \& Codd, J. (1997). Cardinal limits: Evidence from language awareness and bilingualism for developing concepts of number. Cognitive Development, 12, 85-106.

Bialystok, E., \& Codd, J. (2000). Representing quantity beyond whole numbers: Some, none and part. Canadian Journal of Experimental Psychology, 54, 117-128. 
Biro, D., \& Matsuzawa, T. (2001). Use of numerical symbols by the chimpanzee (Pan troglodytes): Cardinals, ordinals, and the introduction of zero. Animal Cognition, 4, 193-199.

Boysen, S. T. (1993). Counting in chimpanzees: Nonhuman principles and emergent properties of number. In S. T. Boysen \& E. J. Capaldi (Eds.), The development of numerical competence: Animal and human models (pp. 39-59). Hillsdale, NJ: Erlbaum.

Boysen, S. T., \& Berntson, G. G. (1989). Numerical competence in a chimpanzee (Pan troglodytes). Journal of Comparative Psychology, 103, 23-31.

Boysen, S. T., \& Berntson, G. G. (1990). The development of numerical skills in the chimpanzee. In S. T. Parker \& K. R. Gibson (Eds.), "Language" and intelligence in monkeys and apes: Comparative developmental perspectives (pp. 435-450). Cambridge, United Kingdom: Cambridge University Press.

Boysen, S. T., \& Hallberg, K. I. (2000). Primate numerical competence: Contributions toward understanding nonhuman cognition. Cognitive Science, 24, 423-443.

Brannon, E. M., \& Terrace, H. S. (2000). Representation of the numerosities 1-9 by rhesus macaques. Journal of Experimental Psychology: Animal Behavior Processes, 26, 31-49.

Carey, S. (2004, Winter). Bootstrapping \& the origin of concepts. Dædalus, 133, 1-10.

Carey, S., \& Spelke, E. (1994). Domain specific knowledge and conceptual change. In L. Hirshfield \& S. Gelman (Eds.), Mapping the mind: Domain specificity in cognition and culture (pp. 169-200). Cambridge, United Kingdom: Cambridge University Press.

Coull, J. T., \& Nobre, A. (1998). Where and when to pay attention: The neural systems for directing attention to spatial locations and to time intervals as revealed by both PET and fMRI. Journal of Neuroscience, 18, 7426-7435.

Dantzig, T. (1930). Number: The language of science. London: Macmillan. Davis, H., \& Pérusse, R. (1988). Numerical competence in animals: Definitional issues, current evidence, and a new research agenda. Behavioral and Brain Sciences, 11, 561-615.

Dehaene, S. (1997). The number sense. Oxford, United Kingdom: Oxford University Press.

Dehaene, S. (2001). Subtracting pigeons: Logarithmic or linear? Psychological Science, 12, 244-246.

Dehaene, S., Piazza, M., Pinel, P., \& Cohen, L. (2003). Three parietal circuits for number processing. Cognitive Neuropsychology, 20, 487-506.

Fias, W., Lammertyn, J., Reynvoet, B., Dupont, P., \& Orban, G. A. (2003). Parietal representation of symbolic and nonsymbolic magnitude. Journal of Cognitive Neuroscience, 15, 47-57.

Fischer, J.-P. (1992). Subitizing: The discontinuity after three. In J. Bideaud, C. Meljac, \& J.-P. Fischer (Eds.), Pathways to number (pp. 191-208). Hillsdale, NJ: Erlbaum.

Fuson, K. C. (1988). Children's counting and concepts of number. New York: Springer-Verlag.

Gallistel, C. R., \& Gelman, R. (1992). Preverbal and verbal counting and computation. Cognition, 44, 4374.

Gelman, R., \& Cordes, S. (2001). Counting in animals and humans. In E. Dupoux (Ed.), Language, brain, and cognitive development: Essays in honor of Jacques Mehler (pp. 279-301). Cambridge, MA: MIT Press.

Gelman, R., \& Tucker, M. (1975). Further investigations of the young child's conception of number. Child Development, 46, 167-175.

Göbel, S. M., Johansen-Berg, H., Behrens, T., \& Rushworth, M. F. S. (2004). Response-selection-related parietal activation during number comparison. Journal of Cognitive Neuroscience, 16, 15361551.

Göbel, S. M., \& Rushworth, M. F. S. (2004). Cognitive neuroscience: Acting on numbers. Current Biology, 14, R517-R519.

Gordon, P. (2004, October 15). Numerical cognition without words: Evidence from Amazonia. Science, 306, 496-499. 
Groen, G. J., \& Parkman, J. M. (1972). A chronometric analysis of simple addition. Psychological Review, 79, 329-343.

Groen, G. J., \& Resnick, L. B. (1977). Can preschool children invent addition algorithms? Journal of Educational Psychology, 69, 645-652.

Huntley-Fenner, G. (2001). Children's understanding of number is similar to adults' and rats': Numerical estimation by 5-7-year-olds. Cognition, 78, B27-B40.

Huttenlocher, J., Jordan, N., \& Levine, S. C. (1994). A mental model for early arithmetic. Journal of Experimental Psychology: General, 123, 284-296.

Jarvis, E. D., Güntürkün, O., Bruce, L., Csillag, A., Karten, H., Kuenzel, W., et al. (2005). Avian brains and a new understanding of vertebrate evolution. Nature Reviews Neuroscience, 6, 151-159.

Jordan, K., Schadow, J., Wuestenberg, T., Jeinze, H.-J., \& Jäncke, L. (2004). Different cortical activations for subjects using allocentric or egocentric strategies in a virtual navigation task. Brain Imaging, 15, 135-140.

Judge, P. G., Evans, T. A., \& Vyas, D. K. (2005). Ordinal representation of numeric quantities by brown capuchin monkeys (Cebus apella). Journal of Experimental Psychology: Animal Behavior Processes, 31, 79-94.

Kahneman, D., Treisman, A., \& Gibbs, B. J. (1992). The reviewing of object files: Object specific integration of information. Cognitive Psychology, 24, 175-219.

Kaufman, E. L., Lord, M. W., Reese, T. W., \& Volkmann, J. (1949). The discrimination of visual number. American Journal of Psychology, 62, 498-525.

Kawashima, R., Taira, M., Okita, K., Inoue, K., Tajima, N., Yoshida, H., et al. (2004). A functional MRI study of simple arithmetic-a comparison between children and adults. Cognitive Brain Research, 18, 225-231.

Kilian, A., Yaman, S., von Fersen, L., \& Güntürkün, O. (2003). A bottlenosed dolphin discriminates visual stimuli differing in numerosity. Learning \& Behavior, 31, 133-142.

Kline, M. (1972). Mathematical thought from ancient to modern times. New York: Oxford University Press.

Lemer, C., Dehaene, S., Spelke, E., \& Cohen, L. (2003). Approximate quantities and exact number words: Dissociable systems. Neuropsychologia, 41, 1942-1958.

Lyon, B. E. (2003, April 3). Egg recognition and counting reduce costs of avian conspecific brood parasitism. Nature, 422, 495-499.

Mandler, G., \& Shebo, B. J. (1982). Subitizing: An analysis of its component processes. Journal of Experimental Psychology: General, 111, 1-22.

Matsuzawa, T. (1985, May 2-8). Use of numbers by a chimpanzee. Nature, 315, 57-59.

McComb, K., Packer, C., \& Pusey, A. (1994). Roaring and numerical assessment in contests between groups of female lions, Pantera leo. Animal Behaviour, 47, 379-387.

Meck, W., \& Church, R. (1983). A mode control model of counting and timing processes. Journal of Experimental Psychology: Animal Behavior Processes, 9, 320-334.

Mix, K., Huttenlocher, J., \& Levine, S. C. (2002). Quantitative development in infancy and early childhood. New York: Oxford University Press.

Murofushi, K. (1997). Numerical matching behavior by a chimpanzee (Pan troglodytes): Subitizing and analogue magnitude estimation. Japanese Psychological Research, 39, 140-153.

Nieder, A., Freedman, D. J., \& Miller, E. K. (2002, September 6). Representation of the quantity of visual items in the primate prefrontal cortex. Science, 297, 1708-1711.

Olson, M. V., \& Varki, A. (2004, July 9). The chimpanzee genome-a bittersweet celebration. Science, 305, 191-192.

Olthof, A., \& Roberts, W. A. (2000). Summation of symbols by pigeons (Columba livia): The importance of number and mass of reward items. Journal of Comparative Psychology, 114, 158-166.

Pepperberg, I. M. (1981). Functional vocalizations by an African Grey parrot. Zeitschrift für Tierpsychologie, 55, 139-160. 
Pepperberg, I. M. (1987). Evidence for conceptual quantitative abilities in the African Grey parrot: Labeling of cardinal sets. Ethology, 75, 37-61.

Pepperberg, I. M. (1988). Comprehension of "absence" by an African Grey parrot: Learning with respect to questions of same/different. Journal of the Experimental Analysis of Behavior, 50, 553-564.

Pepperberg, I. M. (1990). Cognition in an African Grey parrot (Psittacus erithacus): Further evidence for comprehension of categories and labels. Journal of Comparative Psychology, 104, 41-52.

Pepperberg, I. M. (1992). Proficient performance of a conjunctive, recursive task by an African Grey parrot (Psittacus erithacus). Journal of Comparative Psychology, 106, 295-305.

Pepperberg, I. M. (1994). Evidence for numerical competence in an African Grey parrot (Psittacus erithacus). Journal of Comparative Psychology, 108, 36-44.

Pepperberg, I. M. (1998). The African Grey parrot: How cognitive processing might affect allospecific vocal learning. In R. P. Balda, I. M. Pepperberg, \& A. C. Kamil (Eds.), Animal cognition in nature (pp. 381-409). London: Academic Press.

Pepperberg, I. M. (1999). The Alex studies: Cognitive and communicative abilities of Grey parrots. Cambridge, MA: Harvard University Press.

Pepperberg, I. M. (in press-a). Grey parrots do not always "parrot": Roles of imitation and phonological awareness in the creation of new labels from existing vocalizations. Language Sciences.

Pepperberg, I. M. (in press-b). Ordinality and inferential abilities of a Grey parrot (Psittacus erithacus). Journal of Comparative Psychology.

Pepperberg, I. M., \& Brezinsky, M. V. (1991). Acquisition of a relative class concept by an African Grey parrot (Psittacus erithacus): Discriminations based on relative size. Journal of Comparative Psychology, 105, 286-294.

Pepperberg, I. M., \& Gordon, J. D. (2005). Number comprehension by a Grey parrot (Psittacus erithacus), including a zero-like concept. Journal of Comparative Psychology, 119, 197-209.

Pepperberg, I. M., \& Kozak, F. A. (1986). Object permanence in the African Grey parrot (Psittacus erithacus). Animal Learning \& Behavior, 14, 322-330.

Pepperberg, I. M., \& Wilkes, S. R. (2004). Lack of referential vocal learning from LCD video by Grey parrots (Psittacus erithacus). Interaction Studies, 5, 75-97.

Piazza, M., Giacomini, E., Le Bihan, D., \& Dehaene, S. (2003). Single-trial classification of parallel preattentive and serial attentive processes using functional magnetic resonance imaging. Proceedings of the Royal Society of London B: Biological Sciences, 270, 1237-1245.

Premack, D. (1976). Intelligence in ape and man. Hillsdale, NJ: Erlbaum.

Rousselle, L., Palmer, E., \& Noe"l, M.-P. (2004). Magnitude comparison in preschoolers: What counts? Influence of perceptual variables. Journal of Experimental Child Psychology, 87, 57-84.

Rumbaugh, D. M., Savage-Rumbaugh, E. S., \& Hegel, M. (1987). Summation in a chimpanzee (Pan troglodytes). Journal of Experimental Psychology: Animal Behavior Processes, 13, 107-115.

Rumbaugh, D. M., Savage-Rumbaugh, E. S., \& Pate, J. L. (1988). Addendum to "Summation in a chimpanzee (Pan troglodytes)." Journal of Experimental Psychology: Animal Behavior Processes, 14, 118-120.

Shumaker, R. W., Palkovich, A. M., Beck, B. B., Guagnano, G. A., \& Morowitz, H. (2001). Spontaneous use of magnitude discrimination and ordination by the orangutan (Pongo pygmaeus). Journal of Comparative Psychology, 115, 385-391.

Siegler, R. S. (1987). The perils of averaging data over strategies: An example from children's addition. Journal of Experimental Psychology: General, 12, 349-372.

Simon, T. J. (1999). The foundations of numerical thinking in a brain without numbers. Trends in Cognitive Science, 3, 363-365.

Simon, T. J., \& Vaishnavi, S. (1996). Subitizing and counting depend on different attentional mechanisms: Evidence from visual enumeration in afterimages. Perception \& Psychophysics, 58, 915-926. 
Smith, B. R., Piel, A. K., \& Candland, D. K. (2003). Numerity of a socially housed hamadryas baboon (Papio hamadryas) and a socially housed squirrel monkey (Saimiri sciureus). Journal of Comparative Psychology, 117, 217-225.

Sophian, C. (1995). Children's numbers. Madison, WI: Brown and Benchmark.

Spelke, E. S., \& Dehaene, S. (1999). Biological foundations of numerical thinking. Trends in Cognitive Science, 3, 365-366.

Spelke, E. S., \& Tsivkin, S. (2001). Language and number: A bilingual training study. Cognition, 78, 4588.

Thomas, R. K. (1992). Primates' conceptual use of number: Ecological perspectives and psychological processes. In T. Nishida, W. C. McGrew, P. Marler, M. Pickford, \& F. B. M. de Waal (Eds.), Topics in primatology: Vol. I. Human origins (pp. 305-314). Tokyo: University of Tokyo Press.

Thompson, N. S. (1968). Counting and communication in crows. Communications in Behavioral Biology, 2, 223-225.

Trick, L., \& Pylyshyn, Z. (1989). Subitizing and the FNST spatial index model. (COGMEM \#44). University of Western Ontario, London, Ontario, Canada.

Trick, L., \& Pylyshyn, Z. (1994). Why are small and large numbers enumerated differently? A limitedcapacity preattentive stage in vision. Psychological Review, 101, 80-102.

Uller, C., Carey, S., Huntley-Fenner, G., \& Klatt, L. (1999). What representations might underlie infant numerical knowledge? Cognitive Development, 14, 1-36.

von Glasersfeld, E. (1982). Subitizing: The role of figural patterns in the development of numerical concepts. Archives de Psychologie, 50, 191-218.

Walsh, V. (2003). Cognitive neuroscience: Numerate neurons. Current Biology, 13, R447-R448.

Wellman, H. M., \& Miller, K. F. (1986). Thinking about nothing: Development of concepts of zero. British Journal of Developmental Psychology, 4, 31-42.

Xia, L., Emmerton, J., Siemann, M., \& Delius, J. D. (2001). Pigeons (Columba livia) learn to link numerosities with symbols. Journal of Comparative Psychology, 115, 83-91.

Zur, O., \& Gelman, R. (2004). Young children can add and subtract by predicting and checking. Early Childhood Research Quarterly, 19, 121-137. 


\section{Appendix.}

All Trials From Experiment 1

\begin{tabular}{|c|c|c|}
\hline Question & Response & Comment \\
\hline 1. $2+1=?$ & 3 & \\
\hline 2. $4+2=?$ & 6 & \\
\hline 3. $3+1=$ ? & 4 & \\
\hline 4. $1+1=$ ? & 2 & \\
\hline 5. $3+2=?$ & 3,5 & Hits cup with beak, he says " 3 "; experimenter repeats question, he says " 5 " \\
\hline 6. $1+0=?$ & 1 & Trial uses same-size candy hearts \\
\hline 7. $3+3=?$ & 6 & Trial uses same-size candy hearts \\
\hline 8. $0+1=?$ & 1 & \\
\hline 9. $3+0=$ ? & 3 & \\
\hline 10. $2+2=?$ & 4 & \\
\hline 11. $1+4=?$ & 5 & First hits cups, says "blue" (color of cups); experimenter repeats question, he says " 5 " \\
\hline 12. $0+2=?$ & 2 & \\
\hline 13. $4+0=$ ? & 4 & \\
\hline 14. $5+1=$ ? & 6 & \\
\hline 15. $2+3=?$ & 5 & \\
\hline 16. $1+0=$ ? & 1 & \\
\hline 17. $1+1=?$ & 2 & Trial uses same-size candy hearts \\
\hline 18. $1+2=?$ & 3 & \\
\hline 19. $3+3=$ ? & 6 & \\
\hline 20. $0+1=?$ & 1 & \\
\hline 21. $2+0=?$ & 2 & \\
\hline 22. $2+2=?$ & 4 & \\
\hline 23. $3+2=?$ & $2,3,5$ & Looks at, taps each cup, says " 2 ," then " 3 "; experimenter says "total," he says "5" \\
\hline 24. $0+3=?$ & 3 & \\
\hline 25. $1+1=?$ & 5,2 & \\
\hline 26. $1+3=?$ & 4 & \\
\hline 27. $6+0=?$ & 6 & \\
\hline 28. $5+0=$ ? & $6,6,6,6$ & Repeat with 10-15 s, he says "5" \\
\hline 29. $0+1=?$ & 1 & \\
\hline 30. $1+2=?$ & 3 & Trial uses same-size candy hearts \\
\hline 31. $0+5=? *$ & $6,6,6,6$ & Repeat with 10-15 s, he says "5"; uses same-sized hearts \\
\hline 32. $4+0=$ ? & 4 & \\
\hline 33. $0+2=?$ & 2 & \\
\hline 34. $3+0=$ ? & 3 & \\
\hline 35. $1+0=?$ & 1 & \\
\hline 36. $3+3=?$ & 3,6 & \\
\hline 37. $4+1=?$ & 5 & \\
\hline 38. $3+1=$ ? & 3,4 & Trial uses same-size candy hearts \\
\hline 39. $1+5=?$ & 6 & \\
\hline 40. $1+1=?$ & 2 & First says "green wool" (tray cover), then "blue" (cup color), then "2" \\
\hline 41. $0+3=?$ & 3 & \\
\hline 42. $0+1=?$ & 1 & \\
\hline 43. $0+4=?$ & 4 & \\
\hline 44. $2+1=?$ & 3 & \\
\hline 45. $5+0=?$ & 5 & \\
\hline 46. $1+0=?$ & 1 & No response until experimenter queried Griffin \\
\hline 47. $0+6=?$ & 6 & \\
\hline 48. $2+0=?$ & 2 & \\
\hline
\end{tabular}

Note. Order of numbers represents placement on tray.

* Alex is given 10-15 s to respond from here on. 